\title{
Cardiovascular Effects of Budralazine in the Dog
}

\author{
Shigetoshi Chiba, M.D., Kimiaki Saegusa, M.D., \\ Yasuyuki Furukawa, M.D., and Yasuhiro Ogiwara, M.D.
}

\section{Summary}

Cardiovascular effects of budralazine were investigated in isolated and cross-circulated dog atrial preparations. When budralazine was injccted into the jugular vein of the donor dog, a hypotension was produced with slight tachycardia in a dose-related manner. At the same time, slight positive chronotropic and biphasic inotropic effects were induced in the isolated atrium perfused with donor's arterial blood. When budralazine was injected into the cannulated sinus node artery of the isolated atrial preparation, it produced only slight negative chronotropic and inotropic responses, occasionally followed by positive responses. Vehicle injections induced monophasic negative chronotropic and inotropic effects. It is concluded that budralazine has a potent vasodilator action, a reflex-induced sympathomimetic action, but no direct cardiac stimulating properties Moreover, a direct catecholamine releasing action of budralazine does not appear to be prominent.

\section{Additional Indexing Words:}

Isolated dog atrium Budralazine Hydralazine Sinus rate Contractility

WYDRALAZINE is available for the treatment of hypertension. ${ }^{1-4)}$ 1 However, it can also produce serious adverse reactions such as tachycardia. Recently, Saegusa et $a^{(5)}$ demonstrated that hydralazine has marked cardiac stimulating properties in isolated and blood-perfused atrial preparations, showing thesc propertics are mediated via adrenergic mechanisms. In 1974, a new phthalazine derivative, budralazine (DJ-1461), was synthetized and investigated pharmacologically. ${ }^{61-8)}$ Akashi et al ${ }^{7}$ reported that budralazine was characterized by the ability to produce vasodilator, nondiuretic and weak cardiac stimulating effects. Thus, in the present study, we compared the effects of budralazine and hydralazine in cross-circulated

From the Department of Pharmacology, Shinshu University School of Medicine, Matsumoto, Japan.

Address for reprint: Shigetoshi Chiba, M.D., Department of Pharmacology, Shinshu University School of Medicine, Matsumoto 390, Japan.

Received for publication September 4, 1985. 
canine atrial preparations. ${ }^{\text {9)-10) }}$

\section{Methods}

Twenty-two mongrel dogs, weighing 9-21 Kg, were anesthetized with sodium pentobarbital $(30 \mathrm{mg} / \mathrm{Kg}$ ). After i.v. treatment with $200 \mathrm{units} / \mathrm{Kg}$ of sodium heparin, the right atrium was excised and plunged into cold Tyrode's solution at $4-10^{\circ} \mathrm{C}$. The wet weight of the atrial preparation was 5-10 g. The sinus node artery was cannulated via the right coronary artery and perfused with fresh arterial blood conducted from the carotid artery of the donor dog by aid of a peristaltic pump (Harvard Apparatus, model 1210). A pneumatic resistance was placed in parallel with the perfusion system so that the perfusion pressure could be maintained at $100 \mathrm{mmHg}$. The blood flow rate to the isolated atrium was 3 to $8 \mathrm{ml} / \mathrm{min}$. The superior part of the atrium was connected to a force-displacement transducer (Nihon Kohden, AP620G) by a silk thread. The atrium was subjected to a tension of $2 \mathrm{~g}$. The isometric tension was recorded on a direct writing rectigraph (Nihon Kohden, WT-647G). A pair of silver electrodes was placed on the epicardial surface of the isolated atrium to record the electrogram. The atrial rate was measured from the atrial electrogram with a cardiotachometer (Nihon Kohden, AT600G). The donor dogs were anesthetized with $30 \mathrm{mg} / \mathrm{Kg}$ i.v. of sodium pentobarbital and artificially ventilated with room air with a Harvard respirator (model 607). Sodium heparin (500 units/Kg) was administered intravenously at the beginning of the perfusion, and 200 units/Kg was added at l-hr intervals. The systemic blood pressure of the donor was measured from the right femoral artery with a pressure transducer (Nihon Kohden, RP-2), and heart rate was measured with a cardiotachograph triggered by the $\mathrm{R}$ wave of EGG lead II.

The drugs used in this study were budralazine hydrochloride (1-[2-(1,3-

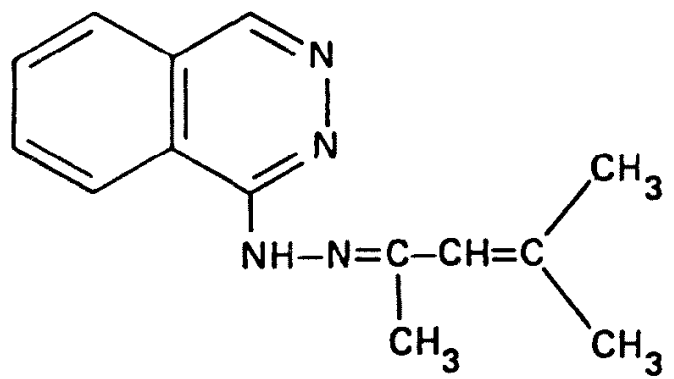

Fig. 1. Chemical structure of budralazine (1-[2-(1,3-dimethyl-2-butenylidene)-hydrazino]-phthalazine). 
dimethyl-2-butenyl-idene)-hydrazino]-phthalazine $\cdot H C l)$ (Daiichi Seiyaku Co., Fig. 1), hydralazine hydrochloride (Daiichi Seiyaku Co.), norepinephrine hydrochloride (Sankyo Co.), atropine sulphate (Takeda Chemical Ind.) and dl-propranolol hydrochloride (Sumitomo Chemicals). Budralazine was dissolved in saline containing a $5 \%$ polyethylene castor oil derivative (Nikko Chemicals, Nikkol CO-40TX) and a 50\% methanol, whereas the others were dissolved in saline.

Each drug was administered into the jugular vein of the donor dog, or into the sinus node artery of the isolated atrium in a volume of $0.01-0.1 \mathrm{ml}$ over a period of $4 \mathrm{sec}$.

Results are expressed as mean \pm SE. The data were evaluated using paired or non-paired Student's t-test and $\mathrm{p}$ values less than 0.05 were regarded as significant.

\section{Results}

Effects of budralazine injected into the donor dog

When budralazine was injected into the jugular vein of the donor dog, a decrease in systemic blood pressure was observed in the donor dog, which
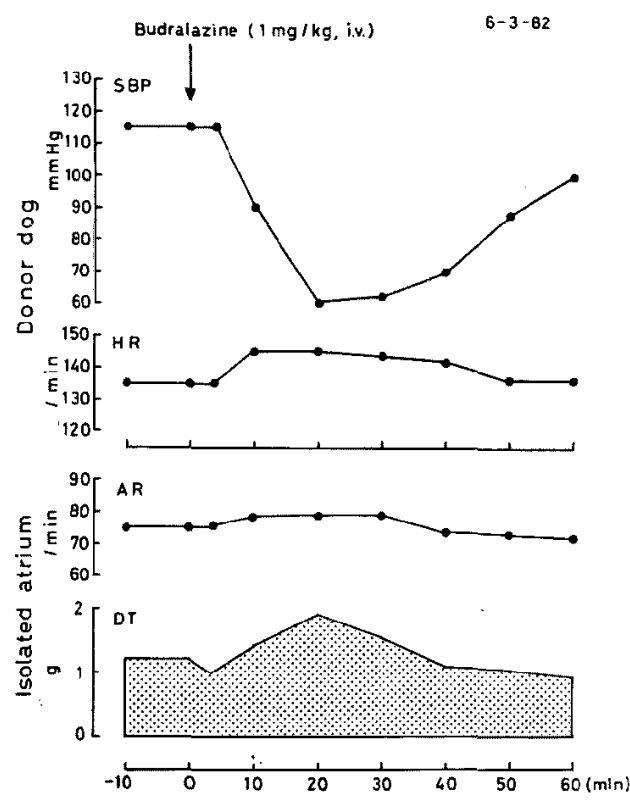

Fig. 2. Cardiovascular effects of $1 \mathrm{mg} / \mathrm{Kg}$ of i.v. budralazine when administered to a donor $\mathrm{dog}$ in a cross-perfused atrial preparation. SBP=systemic blood pressure; $H R=$ heart rate; $A R=$ atrial rate; $D T=$ developed tension. Time shows time after administration. 


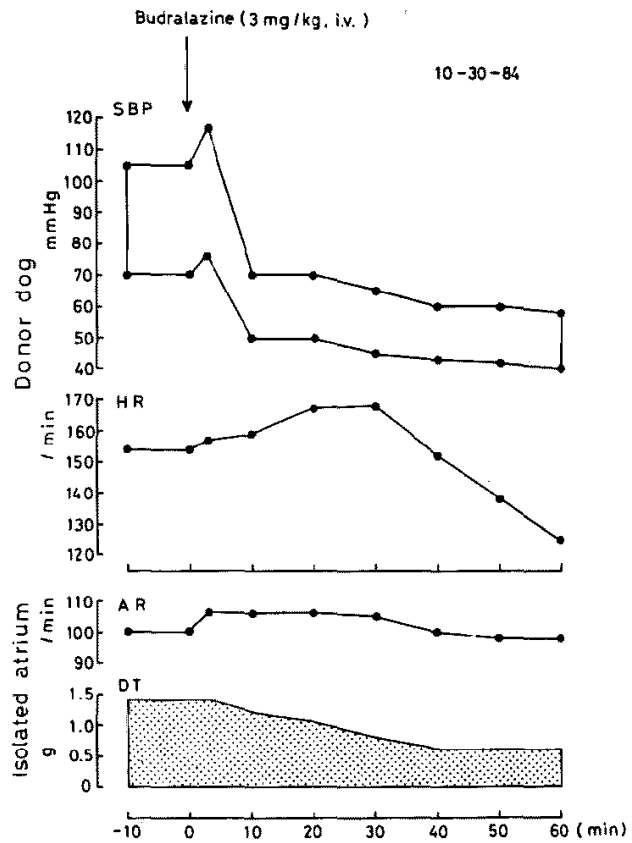

Fig. 3. Cardiovascular effects of $3 \mathrm{mg} / \mathrm{Kg}$ of i.v. budralazine when administered to a donor $\mathrm{dog}$ in a cross-perfused atrial preparation. $\mathrm{SBP}=$ systemic blood pressure; $\mathrm{HR}=$ heart rate; $\mathrm{AR}=$ atrial rate; $\mathrm{DT}=$ developed tension.

was usually accompanied by a slight tachycardia. The threshold dose of budralazine for inducing a hypotension was $300 \mu \mathrm{g} / \mathrm{Kg}$ i.v. One $\mathrm{mg} / \mathrm{Kg}$ of budralazine produced a marked hypotension. Fig. 2 shows from one of the experiments of the effects of $1 \mathrm{mg} / \mathrm{Kg}$ of budralazine injected into the jugular vein of a donor dog. An increase in the heart rate of the donor dog is shown in parallel with a depressor response. In 3 out of 5 experiments, budralazine induced an initial transient bradycardia followed by a slight tachycardia. A relatively larger dose of budralazine occasionally induced an initial increase in systemic blood pressure. Fig. 3 shows the effects of $3 \mathrm{mg} / \mathrm{Kg}$ i.v. of budralazine. This dose caused a profound hypotension with sinus tachycardia, and 50-60 min later bradycardia was observed. At the same time, slight positive chronotropic and negative inotropic responses were observed in the isolated atrium. Intravenous injections of the vehicle caused a slight, but significant depressor response. Data following intravenous injections of budralazine are summarized in Fig. 4. 

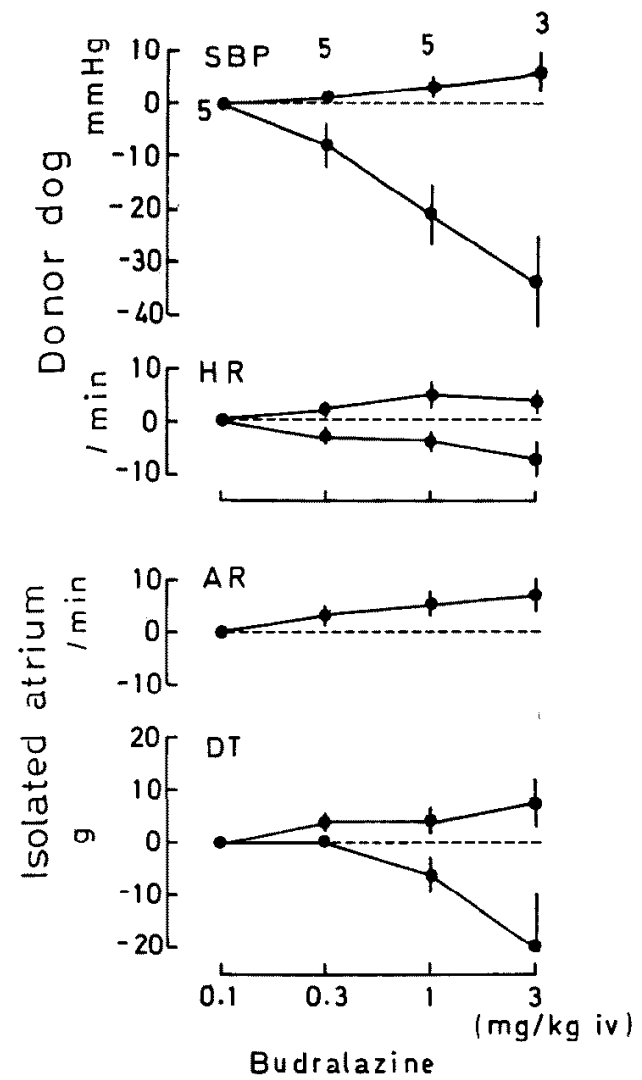

Fig. 4. Summarized data of effects of intravenous injection of budralazine to donor dogs on systemic blood pressure (SBP) and heart rate (HR) in donor dogs and atrial rate (AR) and developed tension (DT) in isolated atria. Each point represents mean value, and vertical lines show standard errors. Numbers represent the number of experiments. Control mean blood pressure was $92 \pm 12 \mathrm{mmHg}$ (mean $\pm \mathrm{SE}$ ), and control heart rate was $152 \pm 16$ beats $/ \mathrm{min}$ in 5 donor dogs. Control atrial rate was $95 \pm 7$ beats $/ \mathrm{min}$, and control developed tension was $2.3 \pm 0.5 \mathrm{~g}$ in 5 atrial muscles.

Effects of injecting hudralazine into the sinus node artery of the isolated and bloodperfused dog atrium

When budralazine was administered into the cannulated sinus node artery of the isolated atrium, negative chronotropic and inotropic effects were usually induced in a dose-related manner. Occasionally, slight positive chronotropic and inotropic effects were observed following profound negative chronotropic and inotropic effects. The same volume of vehicle also induced negative chronotropic and inotropic effects. Fig. 5 shows a tracing of budralazine-, vehicle- and hydralazine-induced chronotropic and inotropic re- 


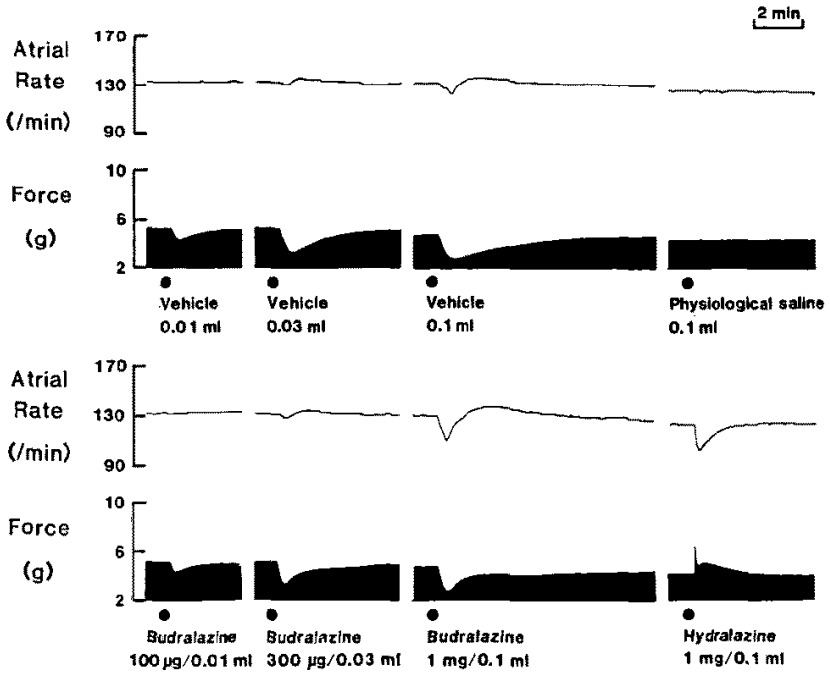

Fig. 5. Chronotropic and inotropic effects of increasing doses of budralazine and its vehicle, and $0.1 \mathrm{ml}$ of physiological saline and $1 \mathrm{mg}$ of hydralazine which were administered into the cannulated sinus node artery of an isolated atrial preparation. Control atrial rate was $119 \pm 6.1$ beats $/$ min (mean $\pm \mathrm{SE}$ ) in 5 preparations. Control developed tension was $3 \pm 0.3 \mathrm{~g}$ (mean \pm $\mathrm{SE})$ in 5 preparations.
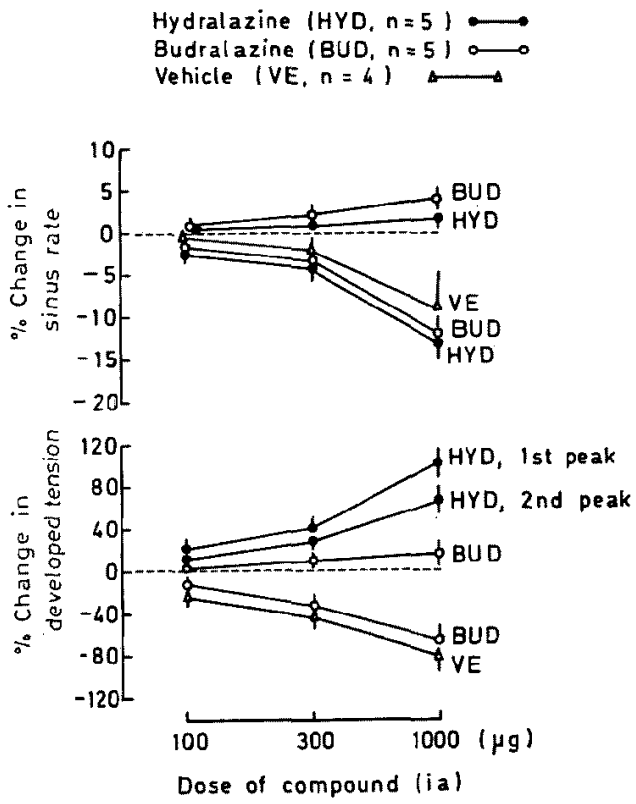

Fig. 6. Summarized data of effects of increasing doses of hydralazine, budralazine and its vehicle, injected into the cannulated sinus node artery of the isolated, blood-perfused atrial preparation. 
sponses in an isolated atrial preparation. Data from all experiments are summarized in Fig. 6. On the other hand, as reported previously, ${ }^{5}$ hydralazine usually induced a biphasic positive inotropic effect in a dose-related manner.

No blocking effect of atropine on budralazine-induced negative chronotropic and inotropic actions

When acetylcholine was injected into the sinus node artery, negative chronotropic and inotropic effects were produced. Acetylcholine (0.1 $\mu \mathrm{g})$ induced negative responses were blocked by $3 \mu \mathrm{g}$ of atropine, but budralazineinduced negative responses were not influenced by a large amount of atropine ( 3 to $30 \mu \mathrm{g}$ ) in 2 experiments. A typical experiment is shown in Fig. 7.

\section{Effects of budralazine and vehicle on electrically paced atrial preparations}

To avoid influences of stimulus frequency on contractile force, atrial muscle was paced electrically with $3 \mathrm{msec}$ duration, $2-5$ volts and $2.5 \mathrm{~Hz}$ stimuli in 2 experiments. As shown in Fig. 8, budralazine induced a dose-

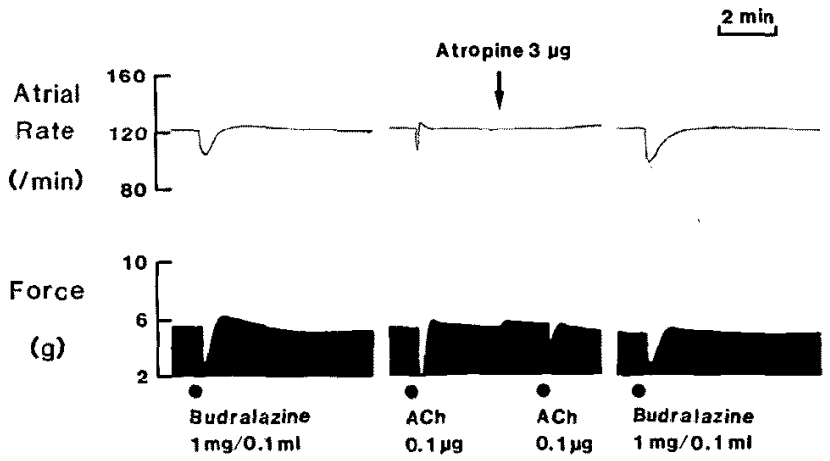

Fig. 7. Effects of $3 \mu \mathrm{g}$ of atropine on acetylcholine (ACh)- and budralazine-induced negative chronotropic and inotropic responses in an isolated atrial preparation.

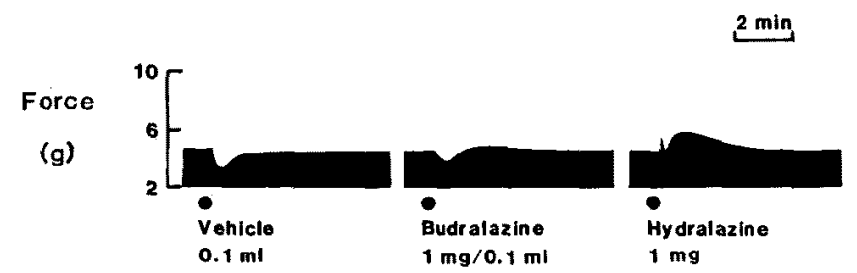

Fig. 8. Inotropic responses to $0.1 \mathrm{ml}$ of vehicle, $1 \mathrm{mg}$ of budralazine and $1 \mathrm{mg}$ of hydralazine in an isolated atrium which was paced at $3 \mathrm{msec}$ duration, 4 volts and $2.5 \mathrm{~Hz}$. 
dependent negative inotropic effect similar to the vehicle. Budralazine also produced a later, slight positive inotropic effect that was not statistically significant. The vehicle also induced a negative inotropic effect. The same dose of hydralazine showed a biphasic positive inotropic effect, consisting of an initial brief effect followed by a relatively long-lasting effect; there was no negative inotropic effect.

\section{Discussion}

In the present study, it was confirmed that intravenous budralazine induces a hypotension with slight tachycardia in pentobarbital-anesthetized dogs, as reported by Akashi et al. ${ }^{71}$ However, we demonstrated two differences from previous results. First, budralazine usually did not show an initial increase in systemic blood pressure. This may be related to the dosage, since we used a relatively small dose range $(0.1-3 \mathrm{mg} / \mathrm{Kg}$, i.v.) compared to the previous study $(6 \mathrm{mg} / \mathrm{Kg}$, i.v.)." Second, intravenous budralazine frequently induced an initial tachycardia followed by bradycardia. Since intravenous budralazine at these doses did not induce a negative chronotropic effect in the isolated atrium which was perfused with donor's blood, these concentrations of budralazine probably do not act directly on SA nodal pacemaker activity, The pentobarbital-anesthetized dog usually maintains a high heart rate. Therefore, intravenous budralazine may cause a decrease in heart rate by changing the tonus of autonomic nervous discharges; for example, by increasing vagal tone or decreasing sympathetic tone in intact animals. In this study, we used cross-perfused atrial muscle which is completely isolated from central nervous factors and found that hypotensive doses of budralazine induced a slight positive chronotropic effect with biphasic inotropic effects in isolated atria. Thus, we concluded that budralazine has direct myocardial depressant properties. In intact animals, intravenous budralazine induces an increase in LV dp/dt and cardiac contractility. ${ }^{7}$ Therefore, cardiac function may modify reflex mechanisms induced by a profound hypotension in intact animals, although budralazine has a slight direct negative inotropic action.

Recently, Saegusa et $\mathrm{al}^{5}$ demonstrated that hydralazine injected into the sinus node artery of the isolated atrium induces biphasic positive inotropic effects. The initial brief peak was not blocked by a beta-adrenoceptor blocking agent, propranolol, and the second peak of relatively long duration was completely blocked by propranolol treatment. Therefore, they concluded that hydralazine has direct cardiac stimulating properties and a direct action on catecholamine release. ${ }^{5)}$ In this study, intravenous budralazine usually 
did not induce an initial positive inotropic effect, but a slight positive inotropic effect following the negative inotropic effect, similar to a second peak of the positive inotropic effect of hydralazine, was occasionally observed. However, a budralazinc-induced positive inotropic effect was unusual and not as prominent as with hydralazine. Thus, budralazine has no direct cardiac stimulating property and no prominent catecholamine releasing action directly from peripheral sympathetic nerve terminals, although it can not be ruled out that the budralazine-induced positive cardiac action may be partially counteracted by the effects of the vehicle. This implies that only a slight effect may appear, because the vehicle for budralazine usually induced a negative inotropic effect. Intraarterial budralazine-induced positive chronotropic and inotropic effects were not significant. On the other hand, intraarterial budralazine usually induced negative chronotropic and inotropic effects, and they were not inhibited by atropine in doses which blocked the acetylcholineinduced effects. From these results, it is concluded that budralazine has direct cardiac depressant properties and may exert its action on catecholamine release primarily by reflex actions.

\section{REFERENCES}

1. Moyer JH: Hydralazine (apresoline) hydrochloride: pharmacological observations and clinical results in the therapy of hypertension. AMA Archs Intern Med $91: 419,1953$

2. Wilkinson EL, Beckman $\mathbf{H}$, Hecht HH: Cardiovascular and renal adjustments to a hypotensive agent (1-hydrazinophthalazine: Ciba BA-5968: apresoline). J Clin Invest 31: 872, 1952

3. Stunkard A, Wertheimer L, Redish W: Studies on hydralazines: evidence for a peripheral site of action. J Clin Invest 33: 1047, 1954

4. Ablad B: A study of the mechanism of the hemodynamic effects of hydralazine in man. Acta Pharmacol Toxicol 20 (suppl 1): 1, 1963

5. Saegusa K, Furukawa Y, Chiba S: Pharmacological analyses of hydralazine-induced cardiac action in intact dogs and isolated, blood-perfused canine atria. J Cardiovasc Pharmacol 8: 1986 (in press)

6. Akashi A, Chiba T, Kasahara A: Antihypertensive activity of 1-[2-(1,3-dimethyl-2-buteny]idene)-hydrazino]-phthalazine (DJ-1461), a new phthalazine derivative. Eur J Pharmacol 29: 161,1974

7. Akashi A, Chiba T, Suzuki I, Hashimoto H: Pharmacology of budralazine, a new antihypertensive drug. Arch Intern Pharmacodyn 235: 134, 1978

8. Chiba T, Shibamura S, Tanaka M, Yamasaki T, Hashimoto H, Kurebayashi Y, Kasai Y, Ryokawa $\mathrm{X}$, Tamura $\mathrm{K}$, Hirohashi $\mathrm{M}$, Akashi A: Antihypertensive and general pharmacological properties of budralazine. Arzneim-Forsch/Drug Res 31: 1080, 1981

9. Chiba S, Kimura T, Hashimoto K: Muscarinic suppression of the nicotinic action of acetylcholine on the isolated, blood-perfused atrium of the dog. Naunyn-Schmiedeb Arch Pharmacol 289: 315, 1975

10. Chiba S, Yabuuchi Y, Hashimoto K: Comparison of the effects of norepinephrine and acetylcholine between intraarterial and extravascular administration to the isolated, bloodperfused canine atrium. Jpn J Pharmacol 25 : 433, 1975 